\title{
Compression Pad Cavity Heating Augmentation on Orion Heat Shield
}

\author{
Brian R. Hollis* \\ NASA Langley Research Center, Hampton, Virginia 23681 \\ DOI: $10.2514 / 1.48076$
}

\begin{abstract}
An experimental study has been conducted to assess the effects of compression pad cavities on the aeroheating environment of the Project Orion Crew Exploration Vehicle heat shield. Testing was conducted in Mach 6 and 10 perfect-gas wind tunnels to obtain heating measurements in and around the compression pads cavities using global phosphor thermography. Data were obtained over a wide range of Reynolds numbers that produced laminar, transitional, and turbulent flow within and downstream of the cavities. The effects of cavity dimensions on boundarylayer transition and heating augmentation levels were studied. Correlations were developed for transition onset and for the average cavity-heating augmentation.
\end{abstract}

\section{Nomenclature}

$D$

$D / H$

$H$

$H_{0}$

$H_{300 \mathrm{~K}}$

$h / h_{\mathrm{FR}}$

$h / h_{\text {Sмоотн }}$

$M_{e}$

$M_{\infty}$

$p_{\infty}$

$q_{\mathrm{FR}}$

$R$

$R e_{\infty}$

$R e_{\theta}$

$R_{n}$

$R_{S}$

$R_{T}$

$T_{\infty}$

$U_{\infty}$

$x$

$y$

$z$

$\alpha$

$\delta$

$\theta$

$\rho_{\infty}$

= cavity diameter, $\mathrm{m}$

$=$ cavity aspect ratio

= cavity depth, $\mathrm{m}$

$=$ total enthalpy, $\mathrm{J} / \mathrm{kg}$ coefficients without cavity

$=$ freestream pressure, $\mathrm{Pa}$ $\mathrm{W} / \mathrm{cm}^{2}$ Reynolds number shoulder, $m$

$=$ freestream velocity, $\mathrm{m} / \mathrm{s}$ $\mathrm{m}$ or in.

$=$ angle of attack, deg
$=$ cold-wall (at $300 \mathrm{~K}$ ) enthalpy, $\mathrm{J} / \mathrm{kg}$

$=$ ratio of measured-to-Fay-Riddell-theory heating

$=$ ratio of measured heating coefficients with and

$=$ boundary-layer-edge Mach number

$=$ freestream Mach number

$=$ heat flux predicted using Fay-Riddell theory,

$=$ maximum vehicle radius, $\mathrm{m}$

$=$ freestream unit Reynolds number, $1 / \mathrm{m}$ or $1 / \mathrm{ft}$

$=$ boundary-layer-edge momentum thickness

$=$ nose (spherical cap) radius, $\mathrm{m}$

$=$ radius at aftbody shoulder, $\mathrm{m}$

$=$ radius at tangency point of spherical cap and

$=$ freestream temperature, $\mathrm{K}$

$=$ distance along vehicle symmetry (roll) axis,

$=$ distance in vehicle yaw-plane, $\mathrm{m}$ or in

$=$ distance in vehicle pitch-plane, $\mathrm{m}$ or in.

$=$ boundary-layer thickness, $\mathrm{m}$

$=$ boundary-layer momentum thickness, $\mathrm{m}$

$=$ freestream density, $\mathrm{kg} / \mathrm{m}^{3}$

\section{Introduction}

$\mathbf{T}$ HE Crew Exploration Vehicle (CEV) concept was defined by NASA's Exploration Systems Architecture Study [1]. This

Presented as Paper 2009-3843 at the 41st AIAA Thermophysics Conference, San Antonio, TX, 22-25 June 2009; received 10 November 2009; revision received 1 October 2010; accepted for publication 12 October 2010. This material is declared a work of the U.S. Government and is not subject to copyright protection in the United States. Copies of this paper may be made for personal or internal use, on condition that the copier pay the $\$ 10.00$ per-copy fee to the Copyright Clearance Center, Inc., 222 Rosewood Drive, Danvers, MA 01923; include the code 0887-8722/11 and \$10.00 in correspondence with the CCC.

${ }^{*}$ Aerospace Engineer, Aerothermodynamics Branch. Senior Member AIAA. study was conducted in 2005 to develop requirements for crew and cargo launch systems to support lunar and Mars exploration programs as well as for access to the International Space Station (ISS). Several versions of the Orion CEV are planned that will provide transportation first to the ISS, then to the moon, and finally to Mars.

The crew module of the CEV (Fig. 1) has a configuration that is outwardly similar to the Apollo command module: a sphericalsegment heat shield joined by a small toroidal section to a truncatedcone-shaped crew compartment. The Orion CEV, however, will be considerably larger than Apollo with a maximum heat-shield diameter of $\sim 5 \mathrm{~m}$ (current configuration) vs $3.912 \mathrm{~m}$ for Apollo. This larger size will allow transport of up to six crew members on ISS missions or up to four crew members on lunar missions.

In a proposed design similar to that of the Apollo program, the CEV crew module will be attached to the service module by six compression pad and tie-rod assemblies (Fig. 2) spaced at $60 \mathrm{deg}$ increments around the heat shield of the vehicle. Because the compression pads and the heat shield will be made from different materials, they will ablate at different rates during reentry and so at different points along the reentry trajectory the compression pads will be either recessed below, or protruding above the heat shield. As evidenced from examination of recovered Apollo heat shield (Fig. 3) the compression pads, whether recessed or protruding, have the potential to cause large, albeit localized perturbations to heating levels as well as to promote boundary-layer transition.

To obtain information to support the design of the CEV heat shield, a parametric investigation of compression pad dimension effects on heating has been performed on a generic CEV design through testing in the Langley Research Center 20 Inch Mach 6 and 31 Inch Mach 10 Air Tunnels. In these tests, global heat-transfer data on the pads and heat shield were obtained using the Langley Research Center thermographic phosphor imaging technique. These tests supplement earlier efforts [2] in which models with the same cavity diameter but with larger cavity depths (hence smaller aspect ratios, $D / H$ ) were tested. Additional data were also drawn from [3] in which various cavity sizes and configurations (including tension ties and annular attachment points) were tested. Supporting information was obtained through computational fluid dynamics predictions for "smoothbody" (no-compression) pads performed at the wind-tunnel test conditions to provide boundary-layer properties for use in correlation of the cavity transition and heating data.

\section{Experimental and Computational Methods}

\section{A. Compression Pad Wind-Tunnel Model Design}

Wind-tunnel models of the CEV vehicle with compression pad cavities were slip-cast in silica-ceramic and coated with a thermographic phosphor compound [4]. The model outer mold line (OML) 

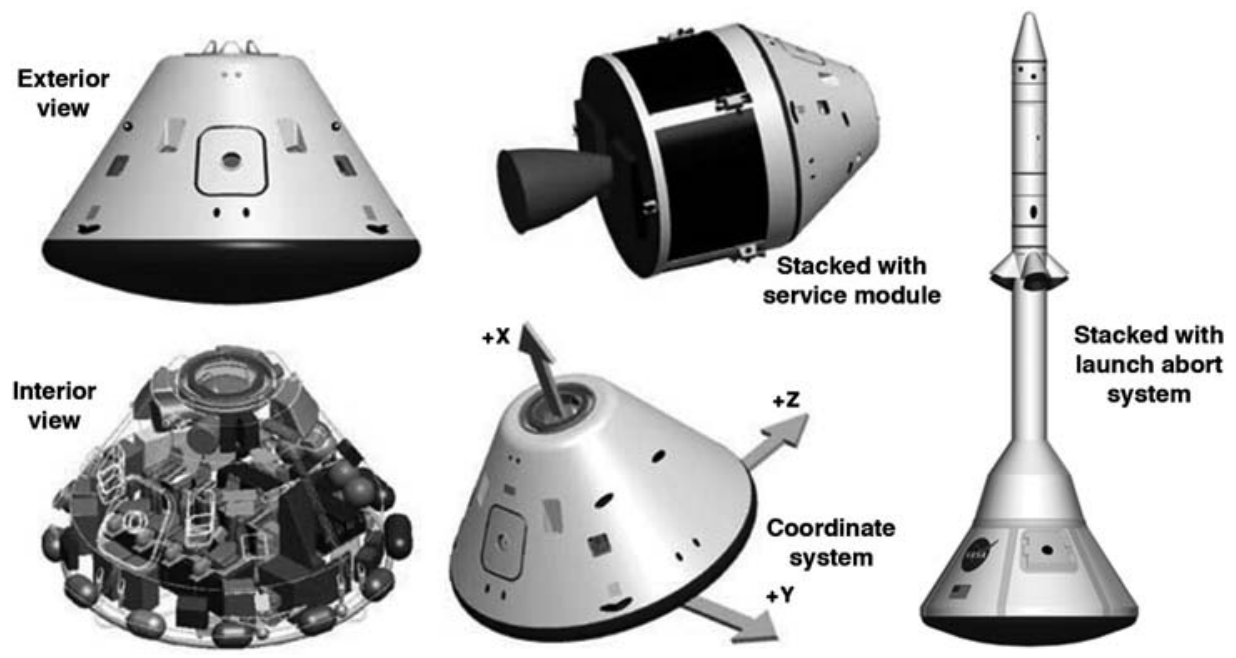

Stacked with

system

Fig. 1 NASA CEV (conceptual artwork).

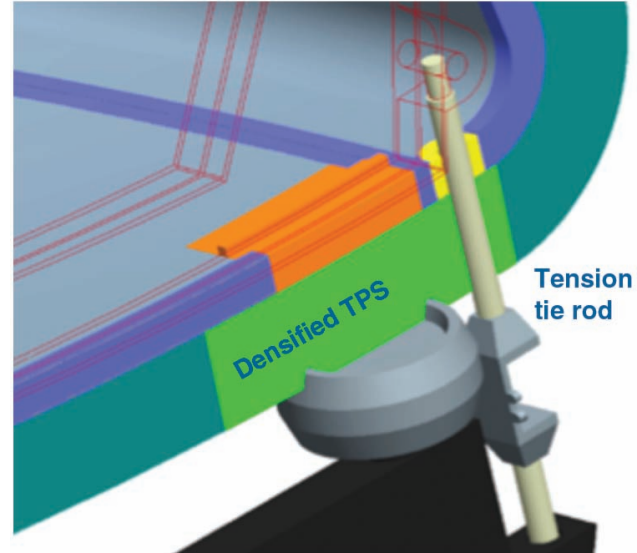

Fig. 2 Generic compression pad/tie-rod assembly for CEV.

was a generic smooth-body representation based on early Project Orion design cycles (Fig. 4). The model scale was 0.03556 (based on an assumed $5.00 \mathrm{~m}$ full scale at the time of the model design) that resulted in baseline 7-in.-max-diam models, although an additional, larger 8-in.-diam model was built to obtain naturally turbulent data. Compression pads were located on each model at $60 \mathrm{deg}$ increments around the circumference of the heat shield at a radial position of $81 \%$ of the maximum radius (Fig. 5). The baseline pad diameter was $0.285 \mathrm{in}$. on the model, which represented full-sized pads of $8.015 \mathrm{in}$. based on geometric scaling. Because the ablation/recession response of the pads and surrounding heat shield are not yet defined and the

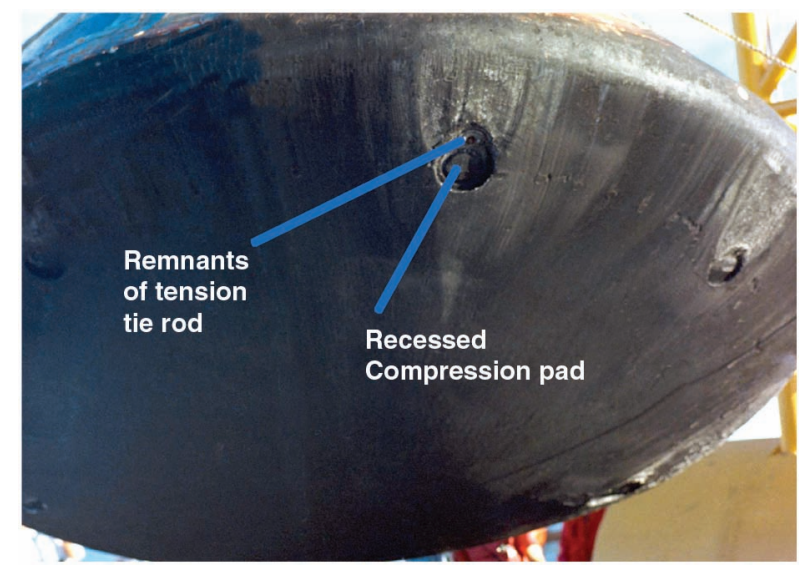

Fig. 3 Effects of compression pad heating on Apollo command module heat shield. compression pad design has not yet been finalized, models with cavity depths of 0.00625 in. (C0-D1 model), 0.0125 in. (C1-D1 model), and 0.0250 in. (C2-D1 model) were fabricated. Crosssectional views of these various cavity geometries are shown in Fig. 6. Also shown in this figure is a larger 0.0500 in. depth model (C3-D1 model) tested in the previous phase of the program [2]; note that the $1 \mathrm{X}$ and $2 \mathrm{X}$ model designations assigned in that test have been redesignated as C2-D1 and C3-D1 for consistency with the current work. A final model (C1-D2) with a depth of 0.0125 in. but with half the nominal diameter ( 0.1425 in.) was also tested and is shown in this figure.

\section{B. Facility Descriptions and Test Parameters}

1. NASA Langley Research Center 31 Inch Mach 10 Air Tunnel

The NASA Langley Research Center 31 Inch Mach 10 Air Tunnel (Fig. 7) is a conventional blowdown facility in which heated, dried, and filtered air is used as the test gas; a detailed description of this facility can be found in [5]. The tunnel has a two-dimensional, contoured nozzle that opens into a 31.0 by $31.0 \mathrm{in}$. test section. The tunnel is equipped with a side-mounted injection system that can transfer a model from the sheltered model box to the tunnel centerline in less than $1 \mathrm{~s}$. Run times of several minutes are possible in this facility, although for aeroheating tests, run times of only a few

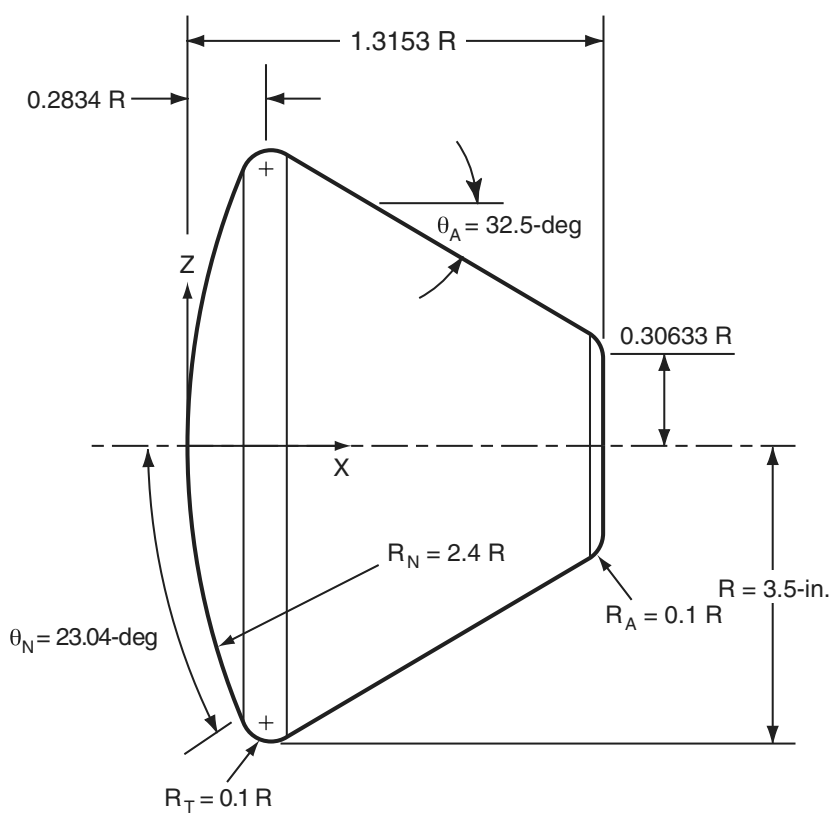

Fig. 4 CEV wind-tunnel model dimensions. 


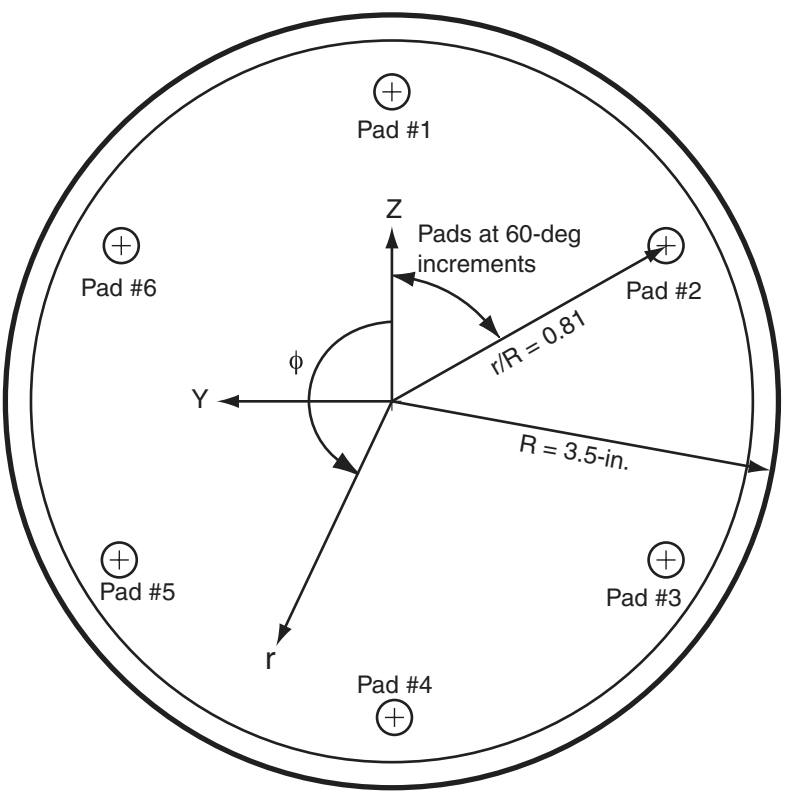

Fig. 5 Compression pad cavity locations.
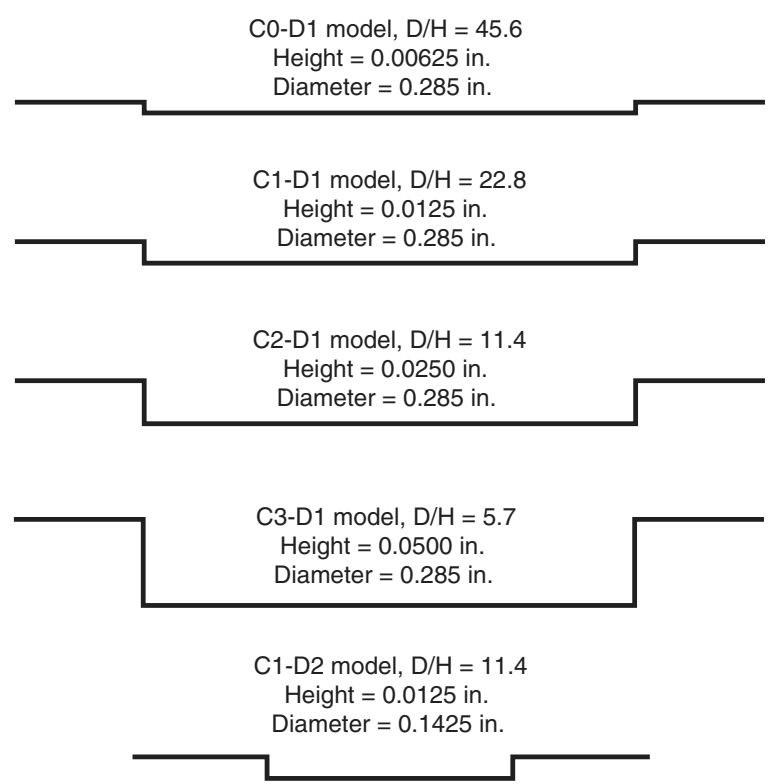

Fig. 6 Compression pad cavity cross sections.

seconds are required. The nominal reservoir conditions of this facility are stagnation pressures of 2.41 to $10.0 \mathrm{MPa}$ (350 to 1450 psia) with a stagnation temperature of $1000 \mathrm{~K}\left(1800^{\circ} R\right)$ that produce perfect-gas freestream conditions of Mach 9.7 to 10.0 at unit Reynolds numbers of $0.5 \times 10^{6}$ to $2.0 \times 10^{6} / \mathrm{ft}\left(1.6 \times 10^{6} 1 / \mathrm{m}\right.$ to $\left.6.6 \times 10^{6} / \mathrm{m}\right)$.

CEV compression pad model heating data were obtained in the Langley Research Center 31 Inch Mach 10 Air Tunnel during Test

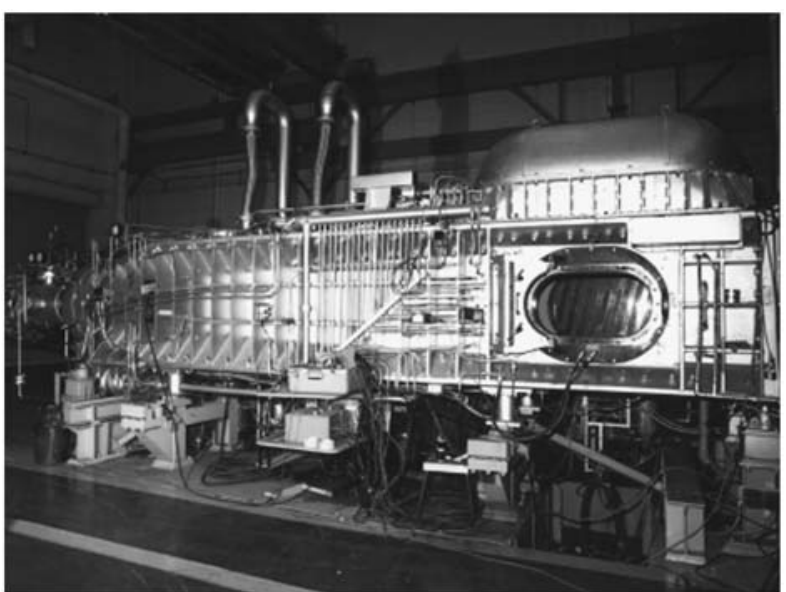

Fig. 7 Langley Research Center 31 Inch Mach 10 Air Tunnel.

456. Test parameters were: angles of attack $(\alpha)$ of 20,24 , and $28 \mathrm{deg}$ and freestream unit Reynolds numbers $\left(R e_{\infty}\right)$ of $0.5 \times 10^{6}$ to $1.2 \times 10^{6} / \mathrm{ft}$. Nominal conditions for each of the test Reynolds numbers are given in Table 1; run-to-run variations in conditions were less than $\pm 1 \%$. For all test conditions, laminar flow was produced upstream of all cavities. The Mach 10 test data obtained during this study on the C2-D1 model supersede the C2-D1 data obtained during the previous [2] Test 446 (under the old 1X model designation). This prior dataset is considered nonoptimal because the model support system had not been designed for that tunnel and positioning of the model to obtain an acceptable viewing angle and sufficient illumination was difficult.

\section{NASA Langley Research Center 20 Inch Mach 6 Air Tunnel}

The NASA Langley Research Center 20 Inch Mach 6 Air Tunnel (Fig. 8) is a blowdown facility in which heated, dried, and filtered air is used as the test gas; a detailed description of this facility can be found in [5]. The tunnel has a two-dimensional contoured nozzle that opens into a $20.5 \times 20.0 \mathrm{in}$. $(0.52 \times 0.508 \mathrm{~m})$ test section. The tunnel is equipped with a bottom-mounted injection system that can transfer a model from the sheltered model box to the tunnel centerline in less than $0.5 \mathrm{~s}$. Run times of up to $15 \mathrm{~min}$ are possible in this facility, although for the current aeroheating study, run times of only a few seconds were required. The nominal reservoir conditions of this facility produce perfect-gas freestream flows with Mach numbers between 5.8 and 6.1 and unit Reynolds numbers of $0.5 \times$ $10^{6} / \mathrm{ft}$ to $7.3 \times 10^{6} / \mathrm{ft}\left(1.64 \times 10^{6}\right.$ to $\left.23.3 \times 10^{6} / \mathrm{m}\right)$.

CEV compression pad model heating data were obtained in the Langley Research Center 20 Inch Mach 6 Air Tunnel during Test 6954. Test parameters were: angle of attack $(\alpha)$ of $24 \mathrm{deg}$ and freestream unit Reynolds numbers $\left(R e_{\infty}\right)$ of $1.0 \times 10^{6}$ to $6.9 \times 10^{6} / \mathrm{ft}$. Nominal conditions for each of the test Reynolds numbers are given in Table 2; run-to-run variations in conditions were less than $\pm 1 \%$. These conditions produced laminar flow upstream of the cavities for Reynolds numbers up to $5 \times 10^{6} / \mathrm{ft}$. At the $R e_{\infty}=6.9 \times 10^{6} / \mathrm{ft}$ condition, transitional flow was produced upstream from the three leeside cavities (pads nos. 6, 1, and 2). The C2-D1 and C3-D1 M 6 data from the previous Test 6946 [2] compression pad study (then with $1 \mathrm{X}$ and $2 \mathrm{X}$ model designations) are also incorporated into the current analysis.

Table 1 Nominal conditions for Langley Research Center 31 Inch Mach 10 Air Tunnel Test 456

\begin{tabular}{ccccccccccc}
\hline \hline$\alpha, \mathrm{deg}$ & $R e_{\infty}, 1 / \mathrm{ft}$ & $R e_{\infty}, 1 / \mathrm{m}$ & $M_{\infty}$ & $P_{\infty}, \mathrm{Pa}$ & $T_{\infty}, \mathrm{K}$ & $\rho_{\infty}, \mathrm{kg} / \mathrm{m}^{3}$ & $U_{\infty}, \mathrm{m} / \mathrm{s}$ & $H_{0}-H_{300 \mathrm{~K}}, \mathrm{~J} / \mathrm{kg}$ & $h_{\mathrm{FR}}, \mathrm{kg} / \mathrm{m}^{2} / \mathrm{s}$ & $q_{\mathrm{FR}}, \mathrm{W} / \mathrm{cm}^{2}$ \\
\hline $20,24,28$ & $5.19 \mathrm{E}+05$ & $1.70 \mathrm{E}+06$ & 9.68 & 68.2 & 52.4 & $4.54 \mathrm{E}-03$ & 1404 & $7.38 \mathrm{E}+05$ & $6.41 \mathrm{E}-02$ & 4.73 \\
$20,24,28$ & $7.01 \mathrm{E}+05$ & $2.30 \mathrm{E}+06$ & 9.73 & 93.9 & 53.3 & $6.15 \mathrm{E}-03$ & 1424 & $7.66 \mathrm{E}+05$ & $7.58 \mathrm{E}-02$ & 5.80 \\
$20,24,28$ & $1.02 \mathrm{E}+06$ & $3.34 \mathrm{E}+06$ & 9.81 & 130.1 & 51.9 & $8.74 \mathrm{E}-03$ & 1415 & $7.53 \mathrm{E}+05$ & $8.97 \mathrm{E}-02$ & 6.75 \\
$20,24,28$ & $1.22 \mathrm{E}+06$ & $4.00 \mathrm{E}+06$ & 9.84 & 159.0 & 52.7 & $1.05 \mathrm{E}-02$ & 1431 & $7.77 \mathrm{E}+05$ & $9.98 \mathrm{E}-02$ & 7.74 \\
\hline \hline
\end{tabular}




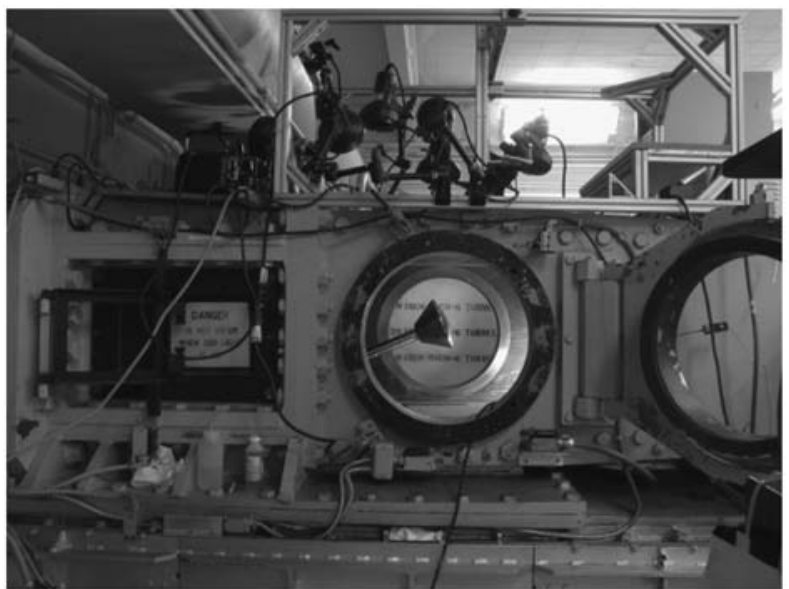

Fig. 8 Langley Research Center 20 Inch Mach 6 Air Tunnel.

\section{Data Acquisition, Reduction, Mapping, and Uncertainties}

1. Data Acquisition and Reduction

Heating levels over the model were measured using the two-color, relative-intensity, global thermographic phosphor method [6,7]. In this method, heat-transfer coefficients are determined by assuming a step-function in heat transfer beginning at injection of the model into the tunnel, which corresponds to a parabolic temperature-time history. The model is illuminated by ultraviolet light sources that produce temperature-dependent fluorescence of the phosphor coating and images of the model are taken in the tunnel before and during a run using a three-color, charge-coupled device camera. The imaging for hypersonic experimental aerothermodynamic testing (IHEAT) code uses calibrations to convert the intensity data from each image pixel to temperatures and then performs the heat-transfer computations. Heat-transfer distributions from IHEAT are expressed in terms of the ratio $h / h_{\mathrm{FR}}$, where $h_{\mathrm{FR}}$ is the heat-transfer coefficient resulting from a Fay-Riddell computation [8] for the heat transfer to a sphere with the radius of curvature of the CEV heat shield (8.4 in./ $0.21336 \mathrm{~m}$ ) at a wall temperature of $300 \mathrm{~K}$

\section{Data Mapping}

The image data obtained from IHEAT were corrected for optical perspective effects and mapped to a three-dimensional surface model of the CEV geometry with compression pads. To accomplish this mapping, perspective transformations are first performed on the three-dimensional surface geometry until its two-dimensional projection matches that of the two-dimensional image data. The image data are then assigned transformed $(x, y, z)$ coordinates based on interpolation between the image and surface geometry, and then the transformation is inverted to obtain a corrected three-dimensional heating distribution. One refinement to this process has been made since its original use in the earlier compression pad test [2]. Instead of interpolating an $(x, y, z)$ coordinate onto each image pixel, the image pixel heating data are instead interpolated onto each $(x, y, z)$ grid point of the surface geometry. While this method introduces some additional error into the interpolation of the image data, which is of much lower resolution than the surface geometry, the final result does not produce jagged edge at the bounds of the image domain and also retains the exact representation of the compression pad geometry.

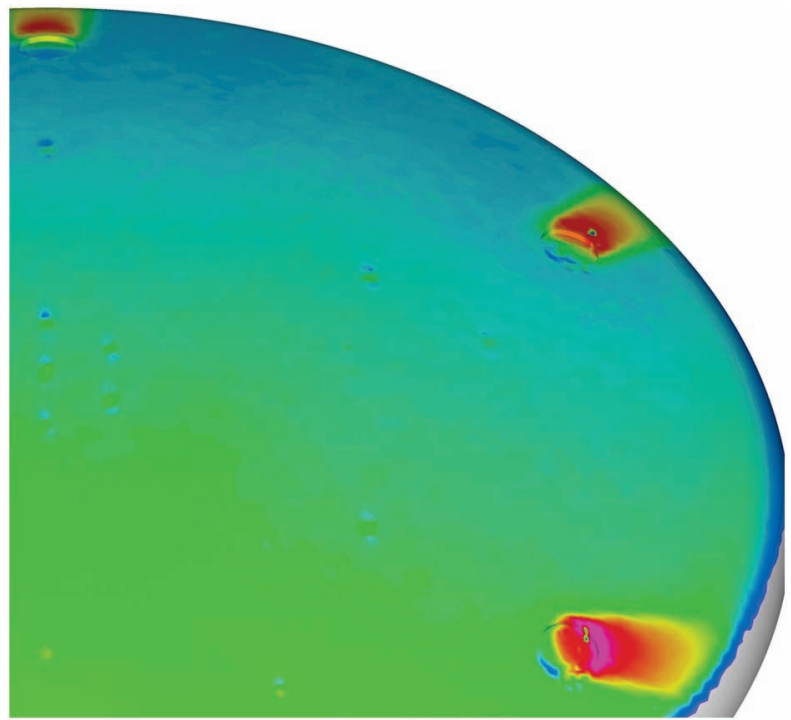

Fig. 9 Sample three-dimensional mapped image data, using interpolation of image pixels to surface geometry.

The differences between these two methods can be seen through comparisons of Figs. 9 and 10.

After mapping the image data to the three-dimensional surface geometry, further information can be obtained by extracting heating distributions along specific line-cut stations. Data were extracted along the pitch-symmetry plane (i.e., the centerline) and along line cuts through the center of each pad that were roughly aligned with the near-surface streamlines at $\alpha=24-\mathrm{deg}$. These compression pad data-cut locations are shown in Fig. 11.

\section{Data Uncertainties}

For testing of a blunt-body configuration such as the CEV, an uncertainty estimate for the measurement technique of approximately $\pm 10 \%$ can be made based on [7]. Additional uncertainties are introduced through the mapping and processing of the data. Uncertainties also are introduced through the variation of windtunnel flow conditions. Since the repeatability of flow conditions is very good, the resulting uncertainty in heating measurements was estimated to be only on the order of $\pm 5 \%$. The other major source of uncertainty that must be considered is the mapping of pixel values from the image data to physical coordinates. This uncertainty is highly problem-dependent: on the overall acreage of a CEV model this uncertainty is estimated to be on the order of $\pm 10 \%$. However, in geometrically-complex regions, such as within/around the compression pads or at the heat-shield shoulder, where the scale of such a feature approaches the resolution of the camera optics, this uncertainty could be much higher. For instance, the localized heating spike observed downstream of a recessed pad's cavity or on the leading edge of a protruding pad may be resolved to only a few image pixels and the resulting geometric uncertainty could be on the order of \pm 25 to $\pm 50 \%$. In the current analysis, the quoted uncertainty for the smooth OML was determined from a root-mean-square summation of that from the acquisition uncertainty $( \pm 10 \%)$, flow conditions $( \pm 5 \%)$, and the acreage estimate for image mapping

Table 2 Nominal conditions for Langley Research Center 20 Inch Mach 6 Air Tunnel Tests 6946 and 6954

\begin{tabular}{ccccccccccc}
\hline \hline$\alpha, \mathrm{deg}$ & $R e_{\infty}, 1 / \mathrm{ft}$ & $R e_{\infty}, 1 / \mathrm{m}$ & $M_{\infty}$ & $P_{\infty}, \mathrm{Pa}$ & $T_{\infty}, \mathrm{K}$ & $\rho_{\infty}, \mathrm{kg} / \mathrm{m}^{3}$ & $U_{\infty}, \mathrm{m} / \mathrm{s}$ & $H_{0}-H_{300 \mathrm{~K}}, \mathrm{~J} / \mathrm{kg}$ & $h_{\mathrm{FR}}, \mathrm{kg} / \mathrm{m}^{2} / \mathrm{s}$ & $q_{\mathrm{FR}}, \mathrm{W} / \mathrm{cm}^{2}$ \\
\hline 24 & $1.07 \mathrm{E}+06$ & $3.51 \mathrm{E}+06$ & 5.89 & 295.3 & 61.5 & $1.67 \mathrm{E}-02$ & 926 & $1.90 \mathrm{E}+05$ & $7.48 \mathrm{E}-02$ \\
24 & $2.08 \mathrm{E}+06$ & $6.83 \mathrm{E}+06$ & 5.96 & 576.3 & 62.2 & $3.23 \mathrm{E}-02$ & 942 & $2.05 \mathrm{E}+05$ & $1.06 \mathrm{E}-01$ & 2.42 \\
24 & $2.94 \mathrm{E}+06$ & $9.63 \mathrm{E}+06$ & 5.99 & 803.0 & 61.8 & $4.53 \mathrm{E}-02$ & 943 & $2.06 \mathrm{E}+05$ & $1.26 \mathrm{E}-01$ & 2.58 \\
24 & $4.05 \mathrm{E}+06$ & $1.33 \mathrm{E}+07$ & 6.01 & 1101.0 & 61.7 & $6.23 \mathrm{E}-02$ & 844 & $2.07 \mathrm{E}+05$ & $1.48 \mathrm{E}-01$ & 3.05 \\
24 & $5.04 \mathrm{E}+06$ & $1.65 \mathrm{E}+07$ & 6.02 & 1415.1 & 63.1 & $7.83 \mathrm{E}-02$ & 957 & $2.21 \mathrm{E}+05$ & $1.68 \mathrm{E}-01$ & 3.71 \\
24 & $6.91 \mathrm{E}+06$ & $2.27 \mathrm{E}+07$ & 6.04 & 1928.7 & 63.0 & $1.07 \mathrm{E}-01$ & 958 & $2.21 \mathrm{E}+05$ & $1.97 \mathrm{E}-01$ & 4.36 \\
24 & $7.46 \mathrm{E}+06$ & $2.45 \mathrm{E}+07$ & 6.04 & 2058.0 & 62.5 & $1.15 \mathrm{E}-01$ & 954 & $2.17 \mathrm{E}+05$ & $2.03 \mathrm{E}-1$ & 4.40 \\
\hline \hline
\end{tabular}




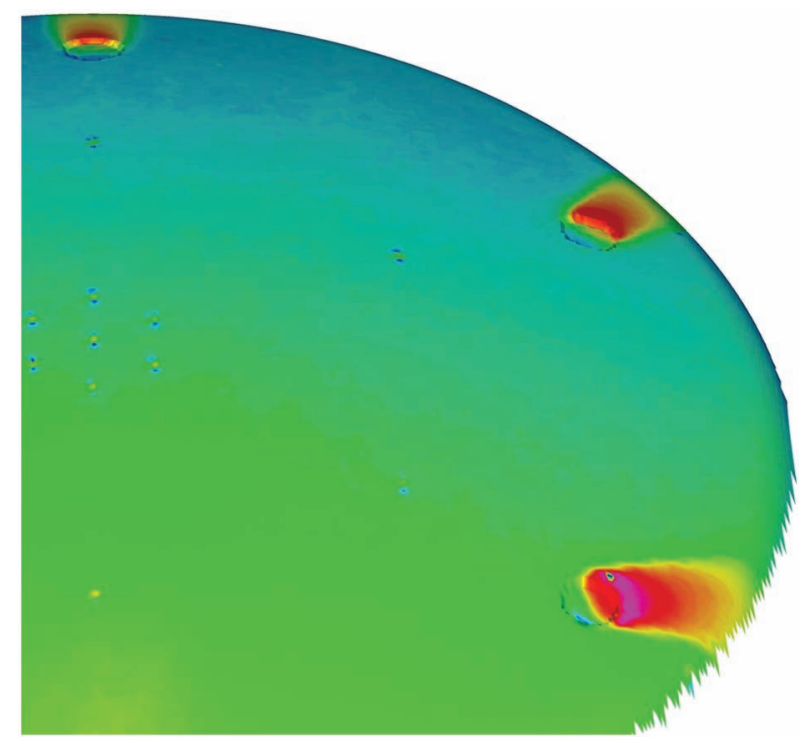

Fig. 10 Sample three-dimensional mapped image data, using interpolation of surface geometry to image pixels.

$( \pm 10 \%)$, which resulted in an overall experimental uncertainty of $\pm 15 \%$. For the heating data in and immediately around the compression pads, the nominal mapping error was set to $\pm 25 \%$ resulting in the overall pad-region uncertainty increasing to $\pm 27 \%$.

\section{Computational Method}

Flowfield predictions were performed using the Langley aerothermodynamic upwind relaxation algorithm (LAURA) code $[9,10]$ to obtain boundary-layer properties (e.g., $R e_{\theta}, M_{e}, \delta$ ) for use in correlating the experimental data. LAURA is a three-dimensional, finite volume solver that includes perfect-gas, equilibrium, and nonequilibrium chemistry models. In this study, the perfect-gas air model was used for the wind-tunnel predictions. Freestream conditions in the Langley Research Center wind tunnels did not vary significantly from run to run, so the nominal conditions in Tables 1 and 2 were used, with the wall temperature set to a constant $300 \mathrm{~K}$. The use of a constant wall temperature was acceptable because the heat-transfer coefficient varies only slightly over the range of wall temperatures produced in these facilities. Solutions were performed

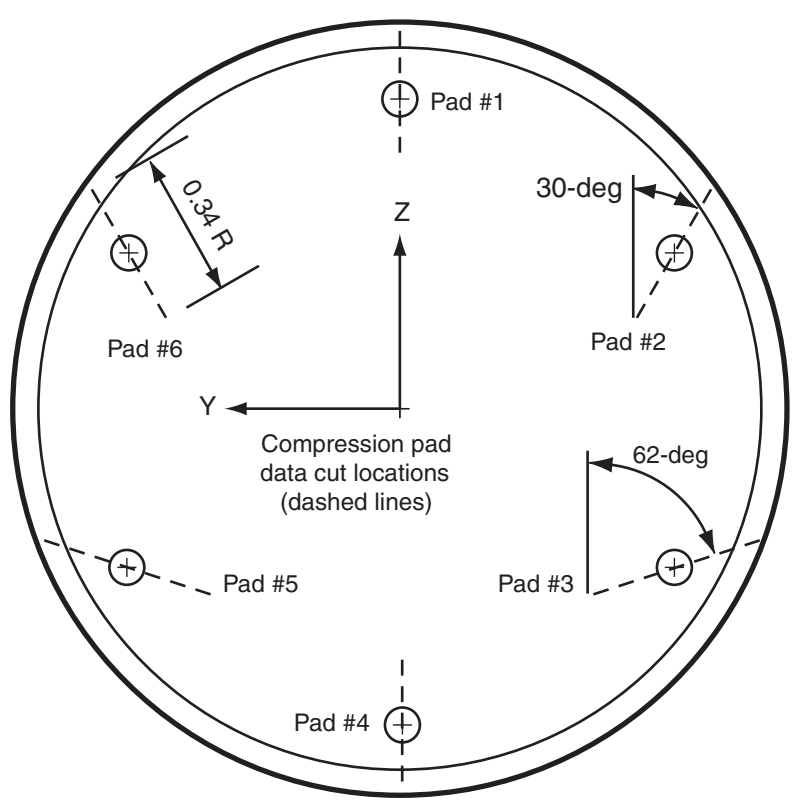

Fig. 11 Compression pad data-cut locations. at all wind-tunnel test conditions on a smooth-OML (no compression pad cavities) grid. The smooth-OML cases were performed using the laminar, thin-layer Navier-Stokes formulation. This methodology has been shown to produce good comparisons with experimental data in previous CEV studies, e.g., [11-13]. For purposes of data correlation and comparisons, heating rates and boundary-layer parameters such as $\operatorname{Re}_{\theta}$ were taken from the OML solutions at locations corresponding to the centers of each pad.

\section{Results and Analysis}

\section{A. Global Effects on Heating}

Sample three-dimensional mapped, global heating images obtained from the Mach 10 and Mach 6 tunnel tests are shown in Fig. 12 in terms of $h / h_{\mathrm{FR}}$. These data are for the C1-D1 model and the images are arranged in order of increasing freestream Reynolds numbers. Data similar in character but of different heating levels were obtained for the other model configurations, although all models were not tested at all Mach 6 and Mach 10 Reynolds numbers.

In these images it can be seen that the flow approaching the cavities was laminar at all test conditions except at the highest Mach 6 test Reynolds number $\left(R e_{\infty}=6.9 \times 10^{6} / \mathrm{ft}\right)$ where transitional flow occurred upstream of the three leeside cavities. In all cases, the compression pad cavities perturbed the incoming flow leading to increased heating downstream of the cavities. For the three lowest Reynolds numbers (all of which are Mach 10 cases), there appeared to be little change in the magnitude of augmented heating downstream of the pads, which indicated that the flow remained laminar; for these three cases, the heating on the cavity floor was also noticeably lower than that upstream of the pad. For $R e_{\infty} \geq$ $1.22 \times 10^{6} / \mathrm{ft}$, the three leeside pads (nos. 1, 2, and 6 at $0 \mathrm{deg}$ and \pm 60 - deg) experienced increasing downstream heating with Reynolds numbers which indicated progression of the boundarylayer state at the pad from transitional to turbulent flow. For the no. 3 and 5 pads (at \pm 120 - deg) similar behavior was observed but with transition onset appearing first at the Mach 6, $R e_{\infty}=2.08 \times 10^{6} / \mathrm{ft}$ condition. Local Reynolds numbers at the no. 4 pad (near the stagnation region) remained very low and transition onset was not observed until the highest Mach 6 Reynolds number condition of $R e_{\infty}=6.91 \times 10^{6} / \mathrm{ft}$.

\section{B. Detailed Cavity-Heating Distributions}

Heating distributions extracted from the image data in Fig. 12 along the line cuts through each pad are shown in Fig. 13. For each pad, the data from all test Reynolds numbers are plotted vs $z / R$ for pad nos. $1,2,4$, and 6 or, to better reflect the orientation of the line cut, vs $y / R$ for pads nos. 3 and 5 . The upstream $h / h_{\mathrm{FR}}$ distributions were nearly constant for all Reynolds numbers except at $R e_{\infty}=$ $6.91 \times 10^{6} / \mathrm{ft}$, which provided evidence that the flow incoming to the pads was laminar for all conditions except at this highest Reynolds number where it was transitional upstream of pads nos. 1 , 2 , and 6. Within the compression pad cavities, the $h / h_{\mathrm{FR}}$ distributions also remained relatively constant at the three lowest Reynolds numbers, again indicating laminar flow. At $R e_{\infty} \geq$ $1.22 \times 10^{6} / \mathrm{ft}$ (depending on the pad location), the $h / h_{\mathrm{FR}}$ distributions began to increase with Reynolds number as is characteristic of transitional or turbulent flow. For all cases, the highest heating levels were produced around the downstream wall and lip of each cavity, which essentially represents a forward facing step.

\section{Cavity-Heating Augmentation}

In the design of the CEV flight vehicle, the heating augmentation above smooth-OML levels in and around the compression pad cavities is of interest; this quantity will be referred to as $h / h_{\mathrm{SMOOTH}}$. To determine this ratio, a smooth-OML reference heating value, $\left(h / h_{\mathrm{FR}}\right)_{\mathrm{SMOOTH}}$, was first determined for each pad at each test condition by averaging the measured heating levels over a small region upstream of the respective pad. The augmentation factor $h / h_{\text {SMоотн }}$ was then computed by dividing the measured $h / h_{\mathrm{FR}}$ 

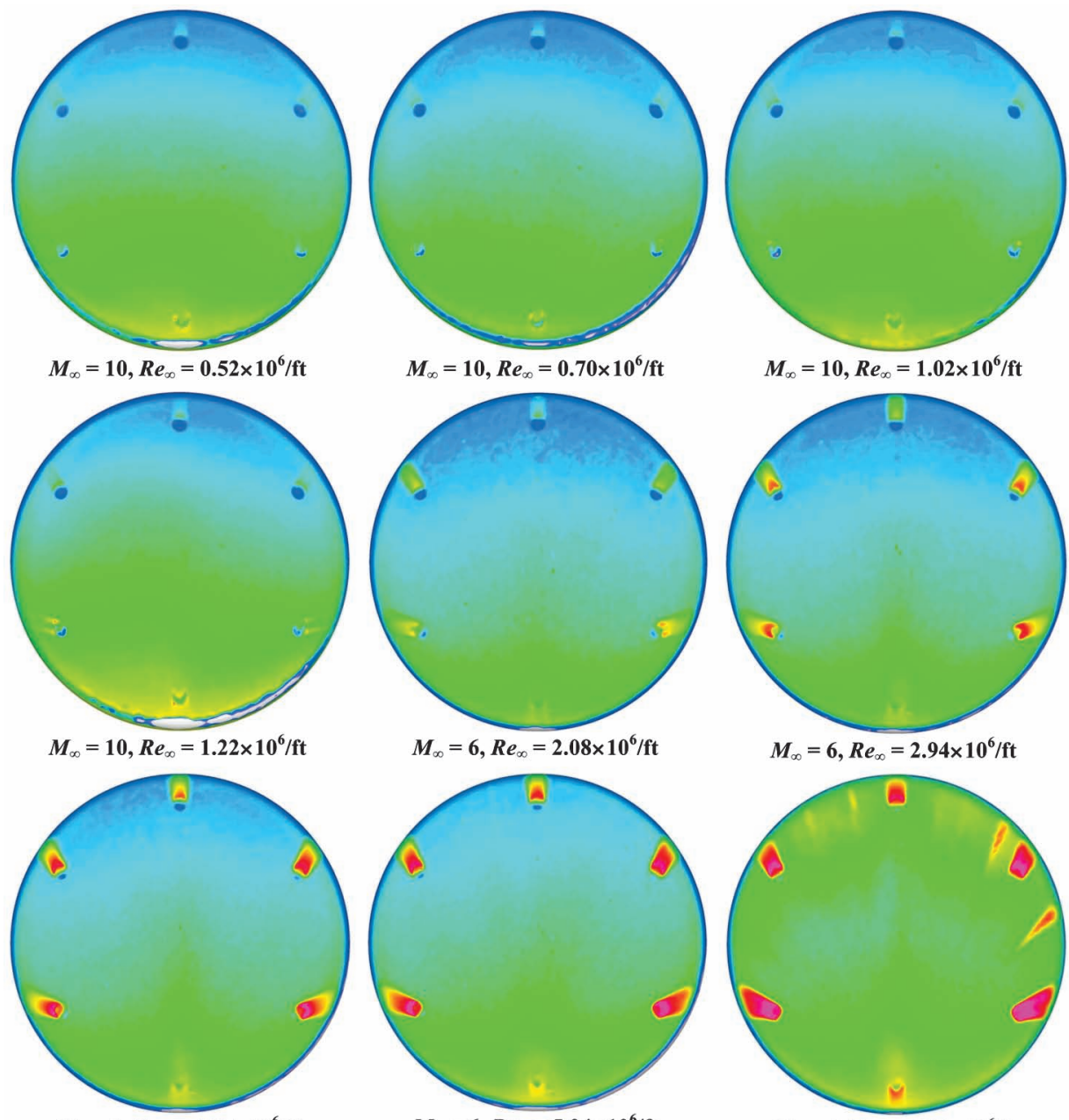

$M_{\infty}=6, R_{\infty}=2.08 \times 10^{6} / \mathrm{ft}$

$M_{\infty}=6, R e_{\infty}=2.94 \times 10^{6} / \mathrm{ft}$
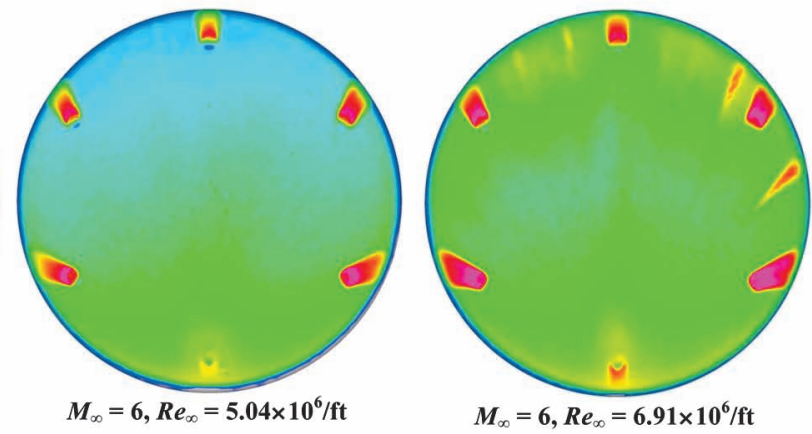

$M_{\infty}=6, R e_{\infty}=4.05 \times 10^{6} / \mathrm{ft}$

$M_{\infty}=6, R e_{\infty}=5.04 \times 10^{6} / \mathrm{ft}$

$M_{\infty}=6, R e_{\infty}=6.91 \times 10^{6} / \mathrm{ft}$

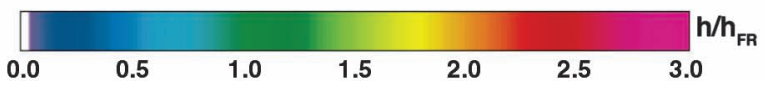

Fig. 12 Global heating distributions measured on C1-D1 model, $\alpha=24-\mathrm{deg}$.

values around each pad by the reference $\left(h / h_{\mathrm{FR}}\right)_{\mathrm{SMOOTH}}$ for that pad. The heating data from Fig. 12 is shown recast in terms of $h / h_{\text {SмоОтн }}$ in Fig. 14.

The augmentation factors were $\sim 1$ around the pads, or $<1$ within the pads, for the lowest Reynolds numbers at which conditions the flow in and downstream of the pads remained laminar. For $R e_{\infty} \geq$ $1.22 \times 10^{6} / \mathrm{ft}$, augmentation factors increased with Reynolds numbers to maximum values around 3 as the flow progressed from transitional to turbulent in and around the pads. Close examination of the augmentation factors around pads nos. 1, 2, and 6 (0 and \pm 60 - deg) shows that the augmentation factors actually decreased at the highest test Reynolds number of $R e_{\infty}=6.91 \times 10^{6} / \mathrm{ft}$. The decrease was due to the definition of the augmentation factor in this analysis, which is the measured pad heating relative to the measured upstream heating. At this highest Reynolds number, the flow upstream of these pads was already transitional and thus the measured reference values were higher than if the flow had remained laminar. So, although the actual dimensional heating was still the highest at this condition, the relative augmentation values were actually slightly lower than those of the next lowest Reynolds number conditions.

\section{Cavity Transition and Average Heating}

\section{Augmentation Correlations}

1. Range of Cavity Average Heating Augmentation Data

Another parameter of interest to design of the CEV flight vehicle is the average heating augmentation over the surface top of each pad (i.e., the cavity floor), which is denoted as $\left(h / h_{\mathrm{SMOOTH}}\right)_{\mathrm{AVG}}$. These values were determined for all pads and test conditions and the resulting values are plotted in terms of the boundary-layer momentum thickness Reynolds number, $R e_{\theta}$, in Fig. 15. These average augmentation factors varied from $\sim 0.5$ to $\sim 3.0$, however, at first glance there seemed to be no correlation with $R e_{\theta}$. Although not shown, a similar lack of correlation was found when the data were plotted against $R e_{\theta} / M_{e}$. The maximum augmentation factors both on and downstream of the pad are also quantities of interest. Maximum values varied between 1 and 4, but the analysis of those data has not yet been completed.

More insight into the physics of this problem can be obtained when the data are color-coded with respect to the state of the boundary layer at and upstream of the compression pad cavities (Fig. 16), as determined by examination of the data plotted and displayed as in Figs. 12-14. For conditions where the incoming flow was laminar and remained laminar downstream of the cavity, the average augmentation $\left(h / h_{\text {SMOотH }}\right)_{\text {AVG }}$ decreased with $R e_{\theta}$ to a minimum value of $\left(h / h_{\mathrm{SMOOTH}}\right)_{\mathrm{AVG}} \sim 0.4$. For cases where the cavity caused transition, average augmentation factors increased to a maximum of $\left(h / h_{\mathrm{SMOOTH}}\right)_{\mathrm{AVG}} \sim 2.5$. And finally, for cases where the incoming flow was transitional or turbulent, the average augmentation factor decreased (as defined relative to measured upstream levels) from the 2.5-maximum value. Of particular interest in this plot is that the average augmentation factor at the pad approaches 1 at the highest Reynolds numbers, which indicates that for fully-turbulent incoming flow conditions, the average pad heating is no higher (approximately) than the incoming turbulent level. 

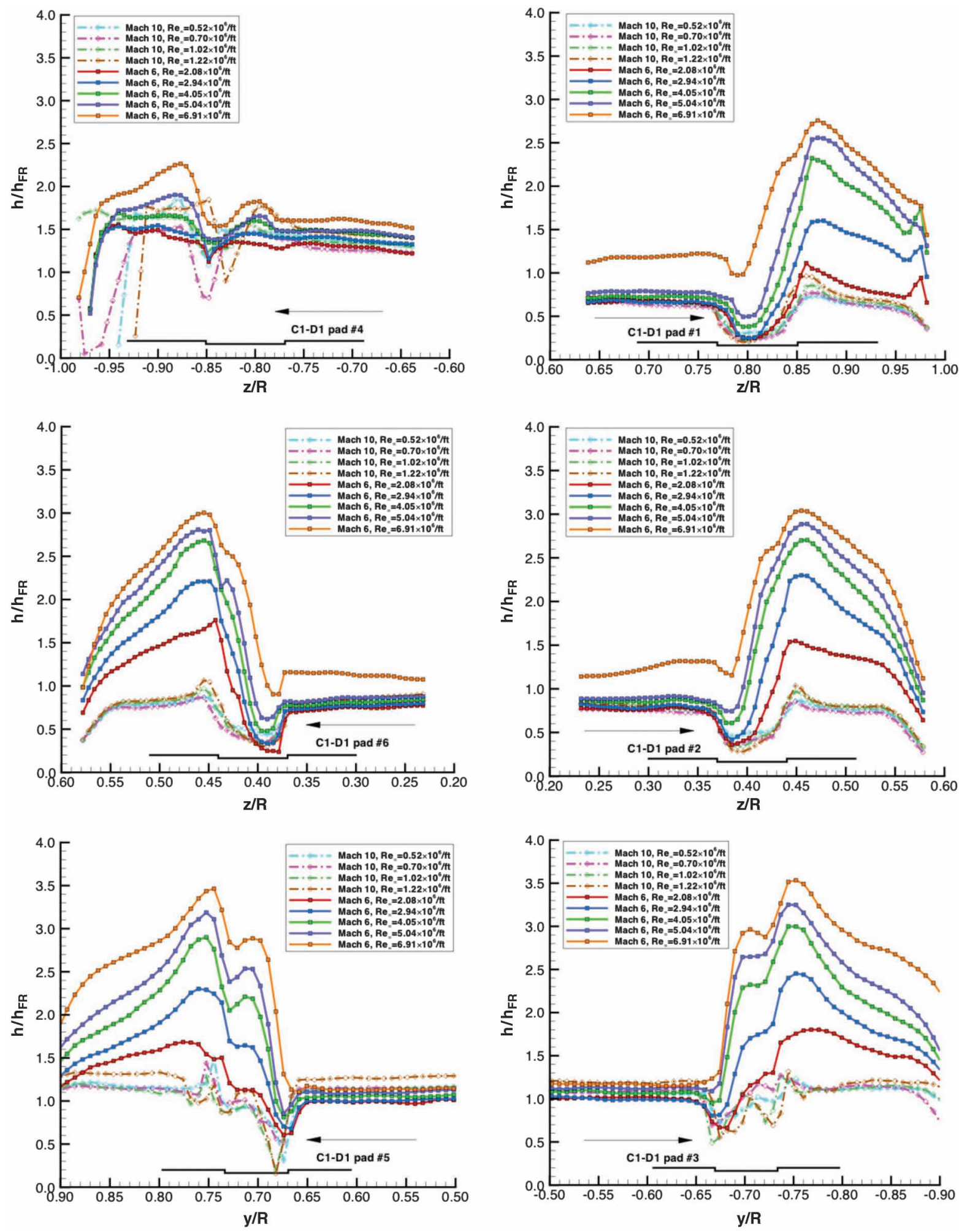

Fig. 13 Heating distributions through C1-D1 model pad centers, $\alpha=24-\mathrm{deg}$.

These data clearly indicate that the cavity effects are a function of the boundary-layer state. Thus, in order to develop a correlation for the heating augmentation factors, a correlation must first be developed that can be used to define the onset of transition at a compression pad cavity.

\section{Crew Exploration Vehicle Closed-Cavity Transition Correlation}

A first attempt at correlating cavity-induced transition on the CEV was performed by applying transition criteria developed for cavities on the Mars Science Laboratory (MSL) heat shield [14-16]. Although the carrier-vehicle attachment points were eventually eliminated from the MSL heat shield by moving them to the aftbody of the vehicle, an extensive database was developed through windtunnel testing and analysis that also included an earlier similar study for the Genesis mission [17]. This database was used to develop the correlations shown in Fig. 17 for cavity size and flow conditions that bound fully-laminar and fully-turbulent flow produced at a cavity.

Transition-onset values were determined from the current CEV data set, as well as from the data in [3], which provided smaller cavity 

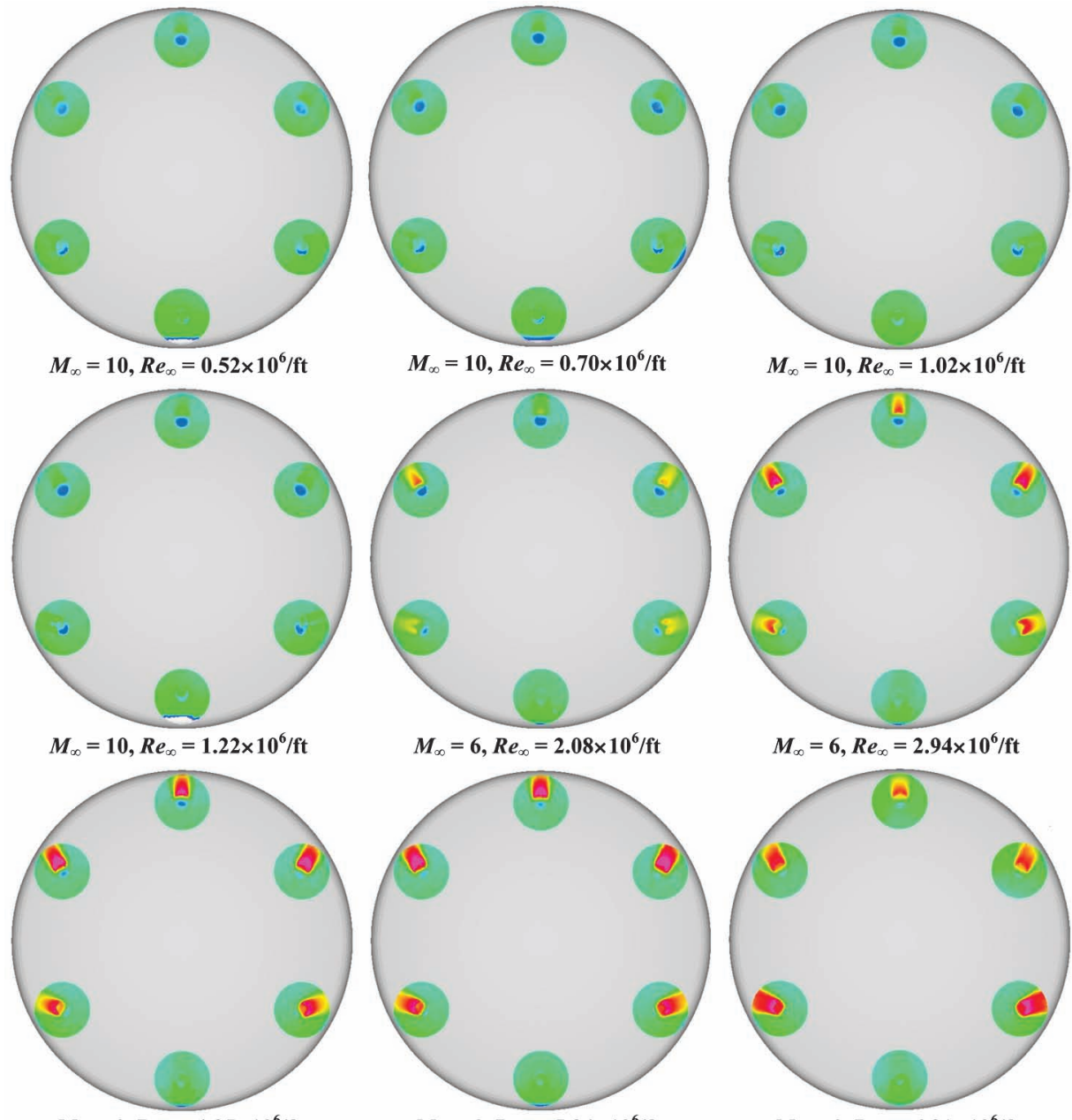

$M_{\infty}=6, R e_{\infty}=2.94 \times 10^{6} / \mathrm{ft}$

$M_{\infty}=6, R e_{\infty}=4.05 \times 10^{6} / \mathrm{ft}$

$M_{\infty}=6, R e_{\infty}=5.04 \times 10^{6} / \mathrm{ft}$

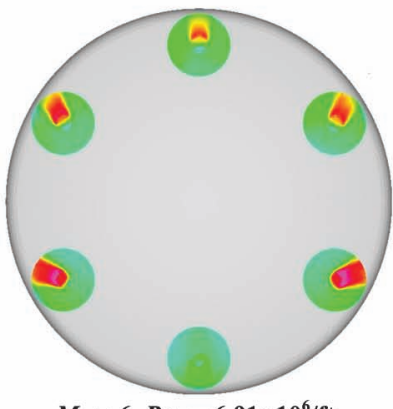

$M_{\infty}=6, R e_{\infty}=6.91 \times 10^{6} / \mathrm{ft}$

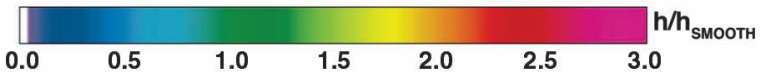

Fig. 14 Heating augmentation factors around C1-D1 model pads, $\alpha=24-\mathrm{deg}$.

aspect ratio data $(D / H=5$ to 10$)$ as well as data $(D / H=11$ to 18$)$ that overlap the current data set $(D / H=11$ to 45$)$. These values are compared with the MSL laminar/transitional boundary in Fig. 18, which is comprised almost entirely of data points from cavities with aspect ratios in the $D / H=1$ to 4 range. Unfortunately, the only CEV

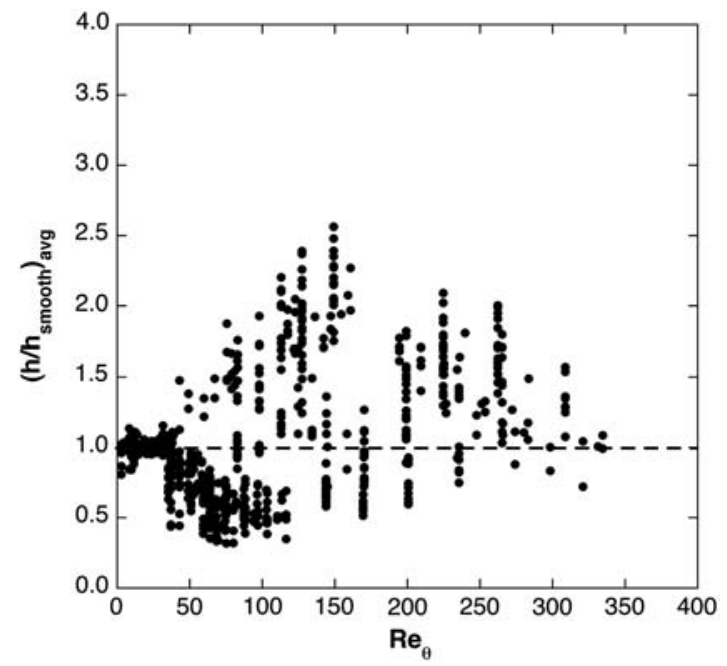

Fig. 15 Average heating augmentation factors for all pads, all test conditions. data that come close to matching the MSL correlation are those for the $D / H=5$ to 6 data; the remaining CEV data clearly diverge farther from the MSL curve as a function of the cavity aspect ratio.

The reason that the MSL correlation does not work for the CEV data is that because of the difference in sizes between the two sets of

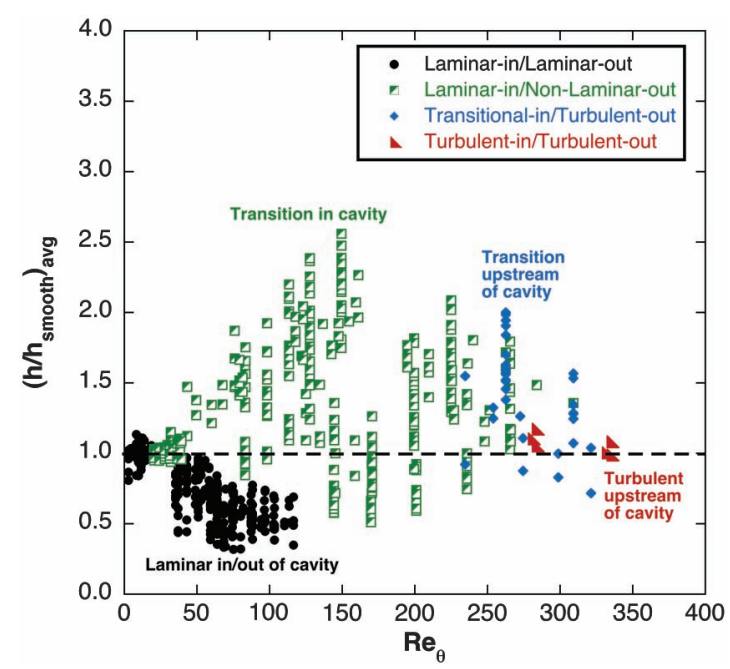

Fig. 16 Average heating augmentation factors classified by boundarylayer state. 


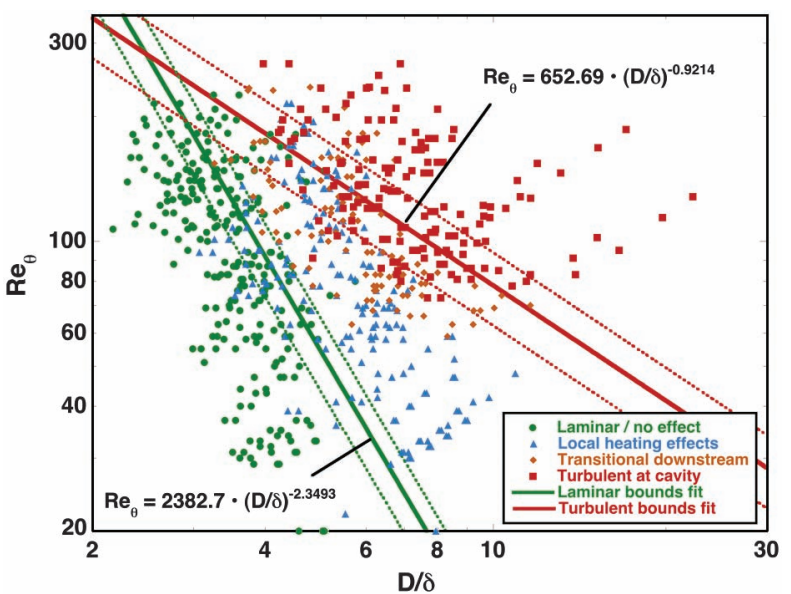

Fig. 17 Laminar and turbulent boundaries from MSL transition study [16].

cavities, the CEV and MSL cavities flows represent different flow regimes. As shown in Fig. 19, a delineation is typically made (e.g., $[18,19])$ between small aspect ratio $(D / H<10)$ and large aspect ratio $(D / H>15)$ cavities. An open cavity (e.g. the MSL data) produces separated, recirculating flow with the cavity, whereas the flow attaches to the cavity floor in a closed cavity (e.g. the majority of the CEV data).

Following the definitions presented in Fig. 19, the C0-D1 and C1-D1 models $(D / H=45.6$ and 22.8 , respectively) can clearly be expected to produce closed-cavity, attached flow, whereas the C3-D1 model $(D / H=5.7)$ should produce open-cavity, separated flow. The C1-D2 and C2-D1 models (both with $D / H=11.4$ ) fall into the intermediate cavity regime, but will provisionally be treated as closed cavities. Additional CEV data from [3] span the range from open to closed-cavity flow.

With respect to the actual CEV flight vehicle, current designs call for very large aspect ratio (wide and shallow) cavity design. Thus, a

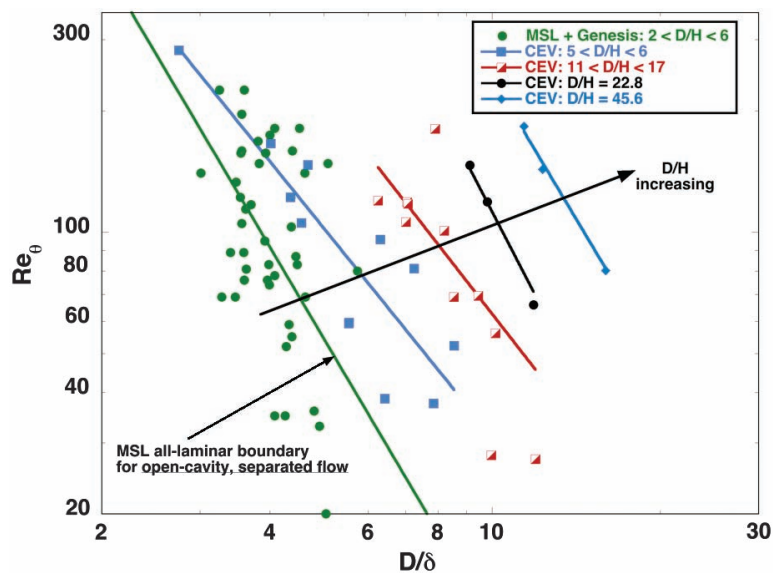

Fig. 18 CEV transition-onset data compared with MSL laminar boundary criterion.

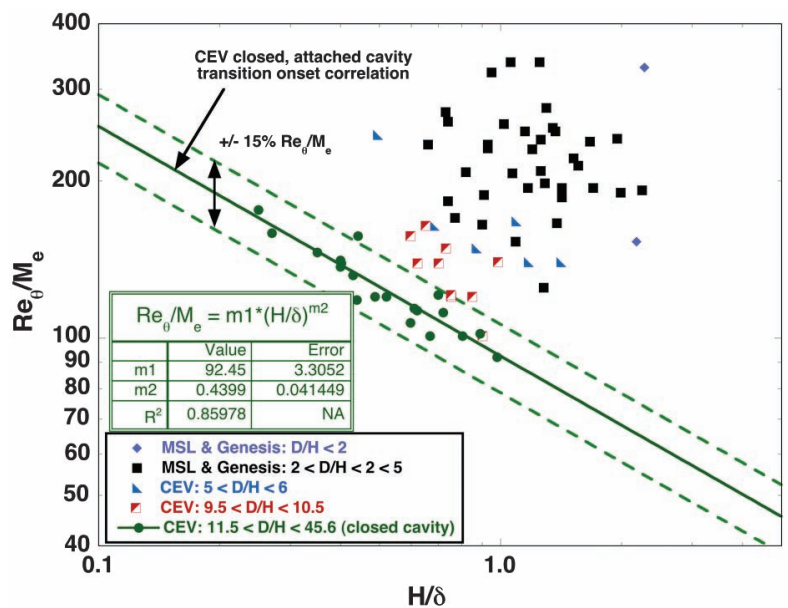

Fig. 20 CEV transition criteria for closed-cavity, attached flow.

transition correlation relevant to closed-cavity, attached flow is required. Because the MSL methodology (in which transition was shown to correlate in terms of $R e_{\theta}$ and the ratio of cavity diameter to boundary-layer height, $D / \delta$ ) was shown to be invalid for CEV, a different functional relationship was required. Since closed-cavity flows produce attached flow on the cavity floor and then the cavity end wall provides the flowfield disturbance that causes transition, an analogy to transition correlations for discrete boundary-layer trips can be made. For such correlations (e.g. [20]), boundary-layer transition is treated as a function of $R e_{\theta} / M_{e}$ (rather than just $R e_{\theta}$ ) and the ratio of trip height (or in this case cavity depth) to boundary-layer thickness, $H / \delta$.

Such a correlation is presented in Fig. 20 based on all CEV data for $11.5<D / H<45.6$. A good fit was produced with a correlation coefficient of 0.86 . The divergence of the open-cavity, separated flow $\mathrm{CEV}, \mathrm{MSL}$ and Genesis data from this fit can also be seen. If the intermediate cavity data $(D / H=11.5$, which are not relevant to current CEV designs) are excluded, the correlation coefficient can be increased to 0.97 as shown in Fig. 21. So, depending on the range and accuracy required, either of the following relations made be used to predict the onset of transition due to compression pad cavities for closed-cavity, attached flows:

$$
\begin{array}{ll}
\frac{R e_{\theta}}{M_{e}}=92.45 \times\left(\frac{H}{\delta}\right)^{-0.43999} & \text { for }\left(\frac{D}{H}\right)>11.5 \\
\frac{R e_{\theta}}{M_{e}}=86.44 \times\left(\frac{H}{\delta}\right)^{-0.49685} & \text { for }\left(\frac{D}{H}\right)>18
\end{array}
$$

Having developed a boundary-layer transition criteria, separate correlations for laminar-in/laminar-out and laminar-in/transitionalor-turbulent-out average heating augmentation factors now can be developed. However, a few provisions on the applicability of all these correlation must first be provided. At the test conditions of this study, the edge Mach numbers on the blunt forebody of the CEV models ranged from $M_{e}=0.1$ to 1.1 ; thus there is little overlap between
Open-cavity, separated flow $\mathrm{D} / \mathrm{H}<10$ (approx.)

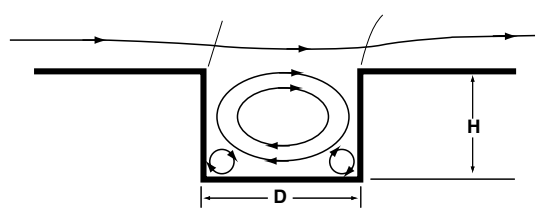

Intermediate cavity

$10<\mathrm{D} / \mathrm{H}<15$ (approx.)

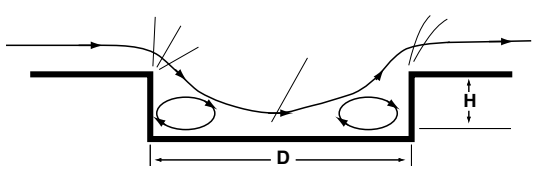

Closed-cavity, attached flow $15<\mathrm{D} / \mathrm{H}$ (approx.)

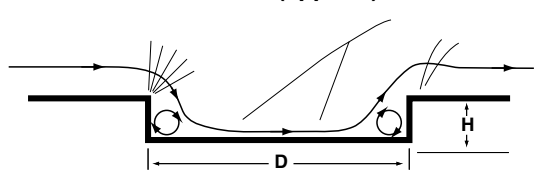

Fig. 19 Illustration of open and closed-cavity flow regimes. 


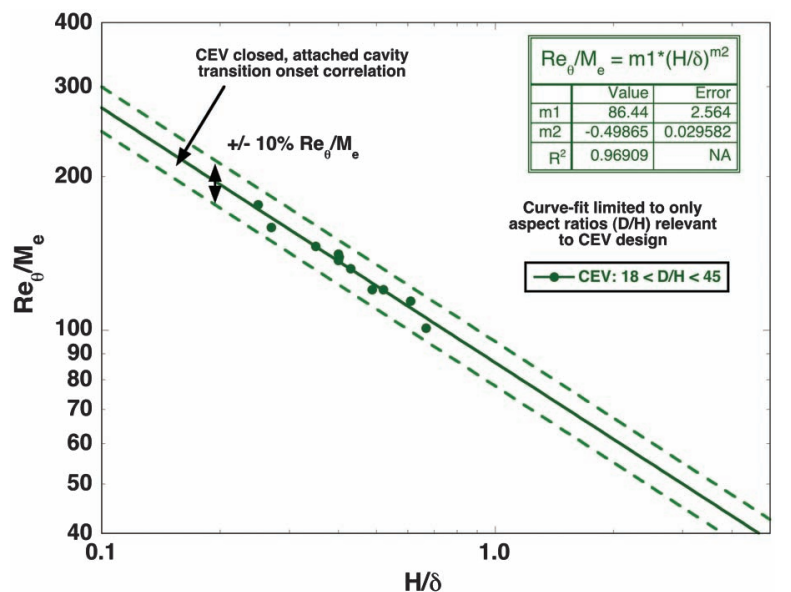

Fig. 21 CEV closed-cavity, attached-flow transition criteria refined to large $(D / H)$.

these data and data on flat plates or lifting vehicles such as the shuttle, $\mathrm{X}-33$, or X-38 with edge Mach numbers ranging from $\sim 1$ to $\sim 4$. Also, these data were obtained in perfect-gas wind tunnel in which the parameters $\delta / \theta$ and $T_{w} / T_{e}$, which are sometimes employed in transition correlations, varied only slightly. Approximate relations for these parameters as a function of $R e_{\theta}$ are provided in Figs. 22 and 23.

\section{Crew Exploration Vehicle Average Cavity-Heating} Augmentation Correlations

The pad-averaged heating augmentation factor data that correspond to laminar-in/laminar-out conditions, as identified using the transition criteria of Eq. (1) or Eq. (2), are plotted in Fig. 24 vs $R e_{\theta}$. These data were sorted by the cavity aspect ratio and showed a clear trend of increasing augmentation with increasing aspect ratio; or, looking at it from the other direction, the cavity floor became cooler as the cavity became deeper. Based on this trend, a correlation variable was defined by dividing $R e_{\theta}$ by the cavity aspect ratio, as shown in Fig. 25. Plotted in this matter, the data showed a clear " $s$-curve" shape with augmentation factors that varied from a maximum of $\sim 1$ to a minimum of $\sim 0.3$. This behavior is similar to that of a hyperbolic tangent function, and so a correlation equation of that form was developed for these data. This laminar-in/laminarout closed-cavity attached-flow augmentation factor correlation is given by

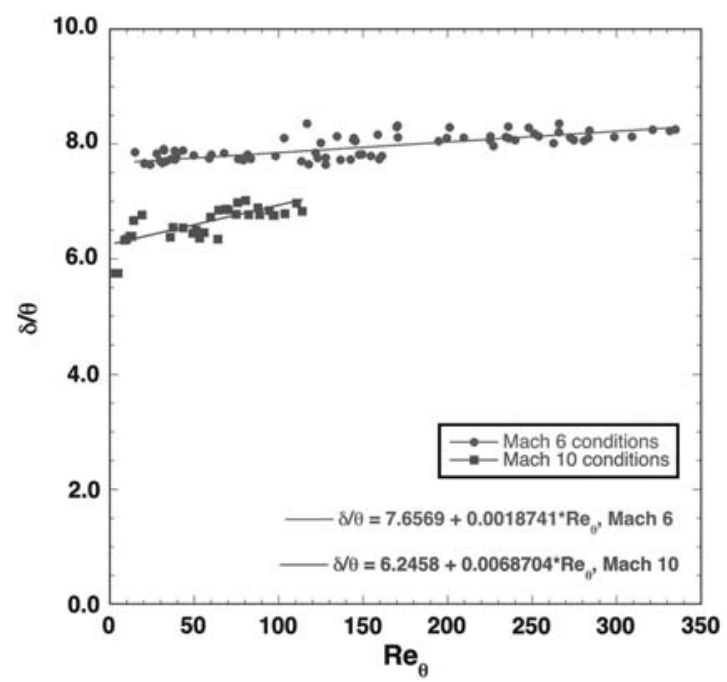

Fig. 22 Approximate relation for variation of $\delta / \theta$ as a function of $R e_{\theta}$ on the CEV models.

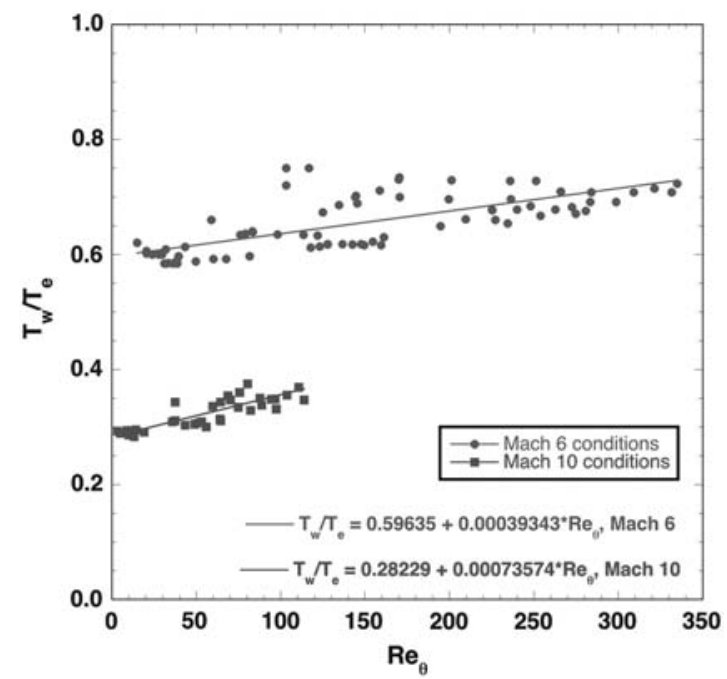

Fig. 23 Approximate relation for variation of $T_{w} / T_{e}$ as a function of $R e_{\theta}$ on the CEV models.

$$
\begin{gathered}
Y=\left(1-\frac{1}{M 1}\right)-\left(\frac{1}{M 1}\right) \times \tanh \left[\frac{2.718(X-M 2)}{M 2}\right] \\
M 1=4.0152, \quad M 2=2.3589 \\
\text { where } X=R e_{\theta} \times\left(\frac{D}{H}\right)^{-1} \text { and } Y=\left(\frac{h}{h_{\mathrm{SMOOTH}}}\right)_{\mathrm{AVG}}
\end{gathered}
$$

This function has a correlation coefficient of 0.787 and fits the majority of the C0-D1 and C1-D1 model cavity data $(D / H$ of 45.6 and 22.8 , respectively) to within $\pm 15 \%$ limits. The major divergences from this curve fit were from the C1-D2 and C2-D1 model data; these two models both had aspect ratios of $D / H=11.5$, which are between the open and closed-cavity limits. There was also fair amount of scatter at the very low $X$ values where the augmentation should ideally approach 1 . These data were mostly from pad no. 4 , which is in the stagnation region. These data were harder to optically acquire than elsewhere on the model because the stagnation region surface was more inclined away from the camera line of sight due to curvature of the model. Also, the boundary-layer variables extracted from the numerical computations are thought to be less well defined since the flow velocity approaches zero at the stagnation point.

The laminar-in/transitional-or-turbulent-out heating augmentation factor data was found to require a different correlation function

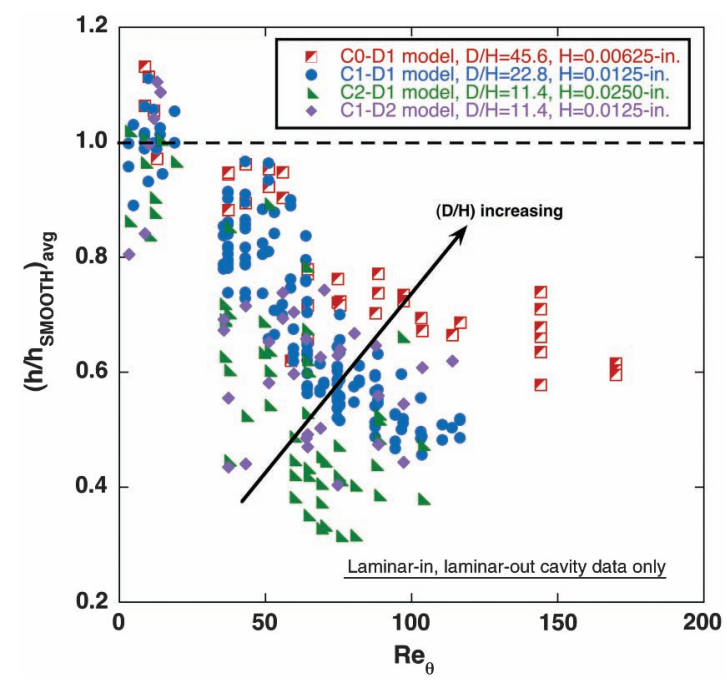

Fig. 24 Laminar, closed-cavity, attached-flow augmentation factors vs $\boldsymbol{R e}_{\theta}$. 


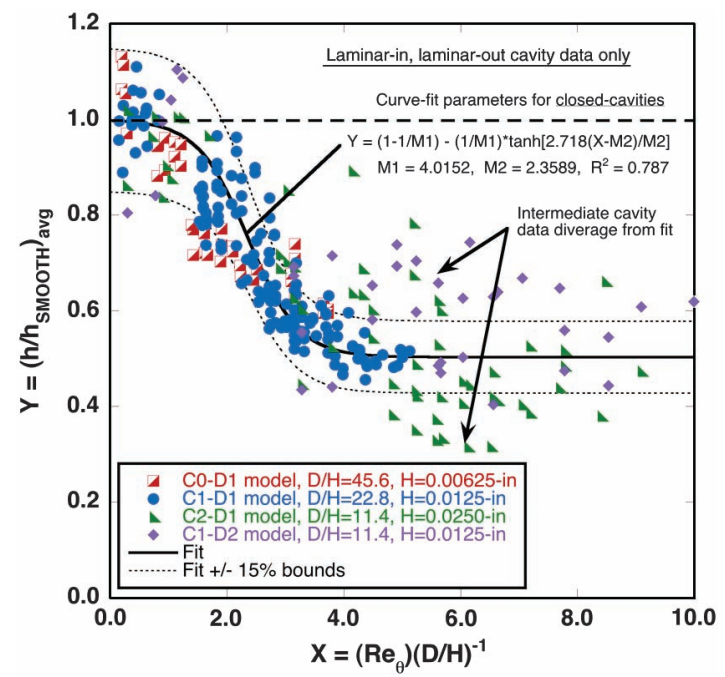

Fig. 25 Correlation function for laminar, closed-cavity, attached-flow augmentation factors.

than the laminar-in/laminar-out data. A plot of these data is shown in Fig. 26 in terms of $R e_{\theta}$ with the values color-coded by pad aspect ratio. Three trends were evident from this plot: first, that the augmentation factors increased with $R e_{\theta}$; second, that the augmentation factors increased with pad depth; and finally, that the data from each pad on a given model fell into separate regions.

To collapse these data, they were first plotted in terms of $R e_{\theta} / M_{e}$, as shown in Fig. 27; however considerable spread was still evident. Through a trial-and-error process, it was determined that plotting the data in terms of $\left(\operatorname{Re}_{\theta} / M_{e}\right) \times\left(1 / M_{e}\right)^{1 / 2}$ provided a much better collapse as shown in Fig. 28, although a dependence on aspect ratio was still evident. Additional trial-and-error fitting led to the inclusion of the factor $(D / H)^{-0.24}$ and a final correlation function, as shown in Fig. 29, of the form

$$
\begin{aligned}
& Y=M 1 \times X^{M 2}, \quad M 1=0.003574, \quad M 2=1.2443 \\
& \text { where } X=\left(\frac{R e_{\theta}}{M_{e}}\right)\left(\frac{1}{M_{e}}\right)^{1 / 2}\left(\frac{D}{H}\right)^{-0.24} \text { and } \\
& Y=\left(\frac{h}{h_{\mathrm{SMOOTH}}}\right)_{\text {avg }}
\end{aligned}
$$

As with the laminar augmentation correlation, this function fits the majority of the high cavity aspect ratio data from the C0-D1 and

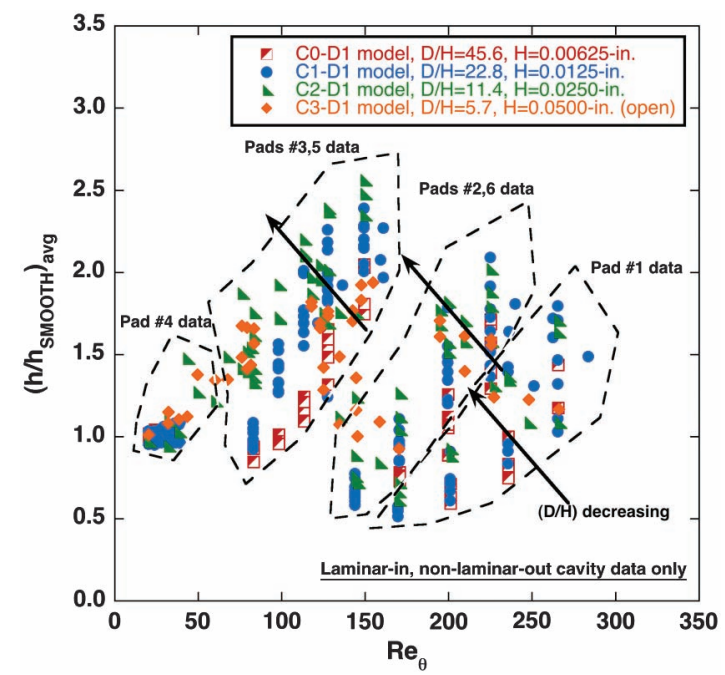

Fig. 26 Transitional/turbulent, closed-cavity, attached-flow augmentation factors vs $\boldsymbol{R} e_{\theta}$.

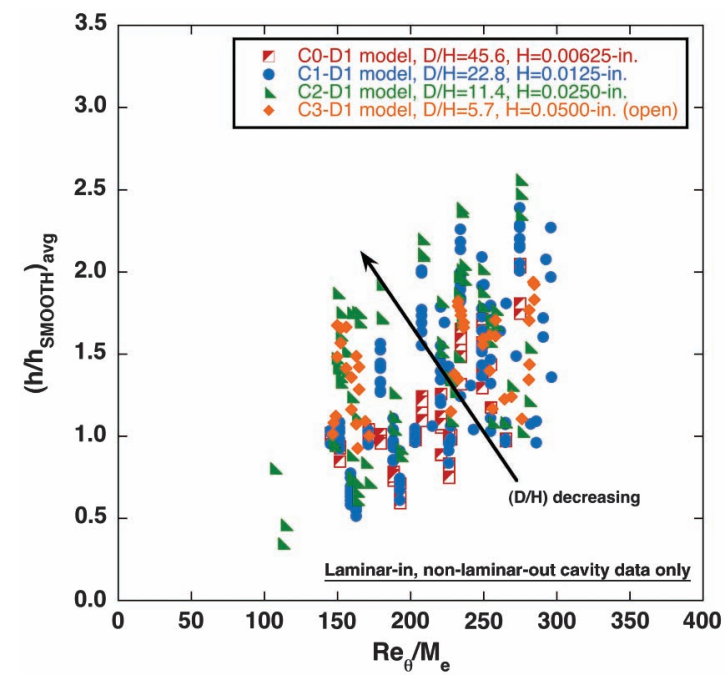

Fig. 27 Transitional/turbulent, closed-cavity, attached-flow augmentation factors vs $R e_{\theta} / M_{e}$.

C1-D1 models to within $\pm 15 \%$ limits. Greater differences were seen in the C2-D1 and C3-D1 model data, which have cavity aspect ratios of 11.5 and 5.7 .

\section{Crew Exploration Vehicle Open-Cavity Correlations}

At this point, no attempt has been made to develop transition or heating augmentation correlations that encompass both open and closed-cavity data since open-cavity flows are not likely to be experienced by the CEV vehicle. However, such correlations for blunt-body, subsonic boundary-layer flow may be possible (if more complex) and will be explored in the future. One such unified open and closed-cavity correlation for supersonic boundary-layer-edge flow has recently been developed for Shuttle Orbiter damage assessment $[21,22]$.

\section{Turbulent and Tripped Data Correlations}

The correlations developed herein do not take into account data from the wind-tunnel tests in which the flow entering the compression pad cavities was already turbulent, whether from natural boundary-layer transition or due to discrete trips placed upstream of the cavities. While these data will be examined, it was shown in Fig. 16 that the augmentation factors (as defined relative to the actual, measured upstream heating) for such cases were actually lower than

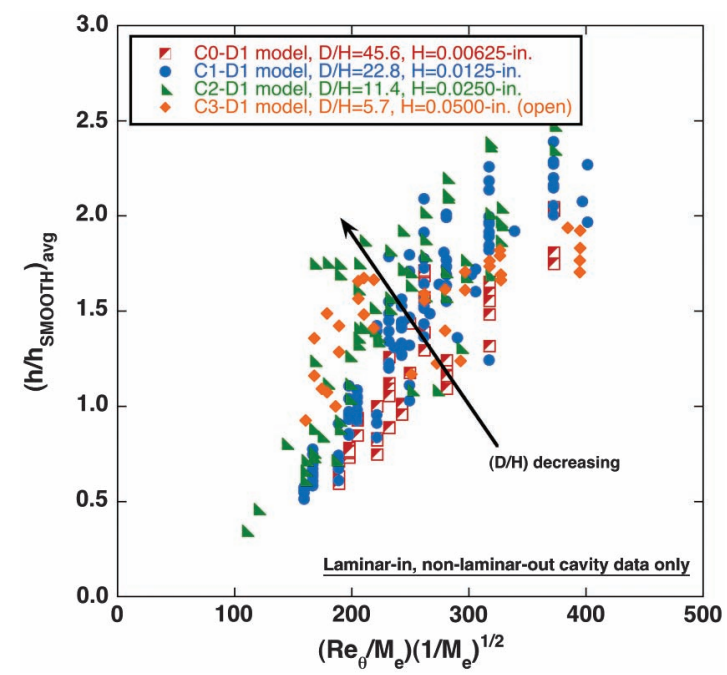

Fig. 28 Transitional/turbulent, closed-cavity, attached-flow augmentation factors vs $\left(\operatorname{Re}_{\theta} / M_{e}\right)\left(1 / M_{e}\right)^{1 / 2}$. 


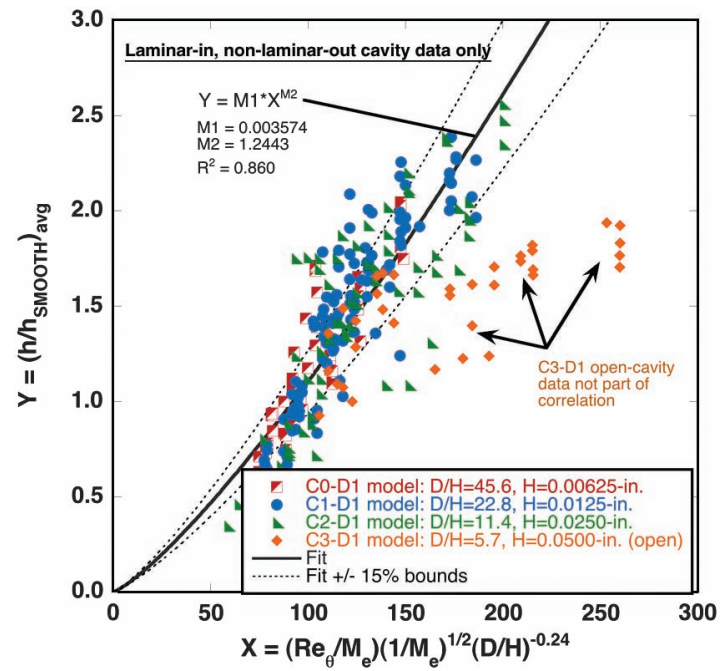

Fig. 29 Correlation function for transitional/turbulent, closed-cavity, attached-flow augmentation factors.

for cases with laminar incoming flow followed by transition produced by the cavity.

\section{Conclusions}

The effects of recessed compression pads on the aeroheating environment of the CEV heat shield have been studied through testing of a CEV models with various cavity dimensions at Mach 6 and 10. Global heating data were obtained and mapped to threedimensional surface geometries and detailed heating distributions were extracted from these maps along line cuts through the center of each pad. Augmentation factors for the cavity effects on heating were determined by taking the ratio of measured heating at and around the pad to that measured on the smooth OML upstream of the pad.

The test conditions provided laminar incoming flow to all pads except for the three leeside pads at the highest test Reynolds number at Mach 6. Depending on pad geometry and local conditions, the boundary-layer state at and downstream of the pads varied from laminar to transitional to turbulent. Compression pad cavity flooraveraged augmentation factors varied from a minimum of approximately 0.3 at laminar-in/laminar-out conditions to a maximum of approximately 2.5 at laminar-in/turbulent-out conditions.

A cavity transition correlation was developed in terms of the boundary-layer parameter $R e_{\theta} / M_{e}$ and the ratio of cavity depth to boundary-layer height, $H / \delta$. This correlation is valid for closedcavity, attached flow with cavity aspect ratios of $D / H>10$, which are applicable values to the design of the CEV vehicle. It was also shown that open-cavity, separated flow $(D / H<10)$ transition data do not fit this correlation; however such values are not within the CEV vehicle design space.

This transition correlation was used to classify the measured augmentation factors as either laminar or transitional/turbulent and separate correlation functions were developed for each data set. A majority of the closed-cavity heating augmentation factor data fell with $\pm 15 \%$ of these correlation fits, while larger differences were evident in the open-cavity data.

\section{References}

[1] "NASA's Exploration Systems Architecture Study, Final Report," NASA TM-2005-214062, Nov. 2005.

[2] Hollis, B. R., "Heating Augmentation in Laminar Flow due to HeatShield Cavities on the Project Orion CEV," AIAA Atmospheric Flight Mechanics Conference and Exhibit, Honolulu, HI, AIAA Paper 20086558, 2008.

[3] Liechty, D. S., "Aerothermodynamic Testing of Protuberances and Penetrations on the NASA Crew Exploration Vehicle Shield," 46th
AIAA Aerospace Sciences Meeting and Exhibit, Reno, NV, AIAA Paper 2008-1240, 2008.

[4] Buck, G. M., "Rapid Model Fabrication and Testing for Aerospace Vehicles," 38th AIAA Aerospace Sciences Meeting and Exhibit, Reno, NV, AIAA Paper 2000-0826, 2000.

[5] Micol, J. R., "Langley Aerothermodynamic Facilities Complex: Enhancements and Testing Capabilities," 36th AIAA Aerospace Sciences Meeting and Exhibit, Reno, NV, AIAA Paper 98-0147, 1998.

[6] Buck, G. M., "Surface Temperature/Heat Transfer Measurement Using a Quantitative Phosphor Thermography System," AIAA Paper 910064, 1991.

[7] Merski, N. R., "Global Aeroheating Wind-Tunnel Measurements Using Improved Two-Color Phosphor Thermography Methods," Journal of Spacecraft and Rockets, Vol. 36, No. 2, March-April 1999, pp. 160170. doi: $10.2514 / 2.3446$

[8] Fay, J. A., and Riddell, F. R., "Theory of Stagnation Point Heat Transfer in Dissociated Air," Journal of Aeronautical Sciences, Vol. 25, No. 2, Feb. 1958, pp. 73-85.

[9] Gnoffo, P. A., "An Upwind-Biased, Point-Implicit Algorithm for Viscous, Compressible Perfect-Gas Flows," NASA TP-2953, Feb. 1990.

[10] Cheatwood, F. M., and Gnoffo, P. A., "User's Manual for the Langley Aerothermodynamic Upwind Relaxation Algorithm (LAURA)," NASA TM 4674, April 1996.

[11] Hollis, B. R., Berger, K. T., Horvath, T. J., Coblish, J. J., Norris, J. D., Lillard, R. P., and Kirk, B. S., "Aeroheating Testing and Predictions for Project Orion CEV at Turbulent Conditions," Journal of Spacecraft and Rockets, Vol. 46, No. 4, July-Aug. 2009, pp. 766-780. doi:10.2514/1.38579

[12] Hollis, B. R., Horvath, T. J., Berger, K. T., Lillard, R. P., Kirk, B. S., Coblish, J. J., and Norris, J. D., "Experimental Investigation of Project Orion Crew Exploration Vehicle Aeroheating in AEDC Tunnel 9," NASA TP-2008-215547, Dec. 2008.

[13] Hollis, B. R., "Experimental Investigation of Project Orion Crew Exploration Vehicle Aeroheating: Langley Research Center 20-Inch Mach 6 Air Tunnel Test 6931," NASA TM-2009-215718, April 2009.

[14] Liechty, D. S., and Hollis, B. R., "Mars Science Laboratory Experimental Aerothermodynamics with Effects of Cavities and Control Surfaces," Journal of Spacecraft and Rockets, Vol. 43, No. 2, March-April 2006, pp. 340-353. doi:10.2514/1.19671

[15] Hollis, B. R., and Liechty, D. S., "Transition due to Heat-Shield Cavities on a Mars Entry Vehicle," Journal of Spacecraft and Rockets, Vol. 43, No. 2, March-April 2006, pp. 354-366. doi:10.2514/1.19669

[16] Hollis, B. R., and Liechty, D. S., "Correlations for Boundary-Layer Transition on Mars Science Laboratory Entry Vehicle due to HeatShield Cavities," NASA TP-2008-215317, June 2008.

[17] Cheatwood, F. M., Merski, N. R., Riley, C. J., and Mitcheltree, R. A., "Aerothermodynamic Environment Definition for the Genesis Sample Return Capsule," 35th AIAA Thermophysics Conference, Anaheim, CA, AIAA Paper 2001-2889, 2001.

[18] Charwat, A. F., Roos, J. N., Dewy, C. F., and Hitz, J. A., "An Investigation of Separated Flow: Part 1, the Pressure Field," Journal of the Aero/Space Sciences, Vol. 28, No. 6, June 1961, pp. 457-470.

[19] Charwat, A. F., Dewey, C. F., Roos, J. N., and Hitz, J. A., "An Investigation of Separated Flow: Part 2, Flow in the Cavity and Heat Transfer," Journal of the Aero/Space Sciences, Vol. 28, No. 7, July 1961, pp. 513-527.

[20] Berry, S. A., and Horvath, T. J., "Discrete Roughness Transition for Hypersonic Flight Vehicles," Journal of Spacecraft and Rockets, Vol. 45, No. 2, March-April 2008, pp. 216-227. doi: $10.2514 / 1.30970$

[21] Everhart, J. L., "Supersonic/Hypersonic Laminar Heating Correlations for Rectangular and Impact-Induced Open and Closed Cavities," Journal of Spacecraft and Rockets, Vol. 46, No. 3, May-June 2009, pp. 545-600. doi:10.2514/1.36830

[22] Everhart, J. L., "Turbulent Supersonic/Hypersonic Heating Correlations for Open and Closed Cavities," Journal of Spacecraft and Rockets, Vol. 47, No. 4, July-Aug. 2010, pp. 545-553. doi:10.2514/1.46877 